J. Dairy Sci. 95:5461-5475

http://dx.doi.org/10.3168/jds.2012-5564

(C) American Dairy Science Association ${ }^{\circledR}, 2012$.

\title{
Invited review: Milk production and reproductive performance: Modern interdisciplinary insights into an enduring axiom
}

\author{
N. M. Bello, ${ }^{\star 1}$ J. S. Stevenson, $†$ and R. J. Tempelman‡ \\ ${ }^{*}$ Department of Statistics, and \\ †Department of Animal Sciences and Industry, Kansas State University, Manhattan 66506 \\ ‡Department of Animal Science, Michigan State University, East Lansing 48824
}

\section{ABSTRACT}

A general belief across the dairy community, both scientific and commercial, is that of an antagonistic association between milk production and reproductive performance of dairy cows. In this article, we critically review the evidence supporting this belief and discuss some of its limitations. Based on the fundamental principles of experimental design and inference, we consider relevant issues that, although critical to the very foundation of the perceived production-reproduction antagonism, seem to have been previously misrepresented or overlooked. In particular, we focus on issues of confounding, randomization, nature of inference, single- versus multiple-trait modeling, cow- versus herdlevel modeling, and scope of inference, all within the context of dairy production systems. Taken together, these issues indicate that the production-reproduction antagonism may not be as pervasive as previously believed, suggesting the need for more rigorous methods of scientific investigation on this matter. We revisit the association between milk production and reproductive performance using a novel interdisciplinary approach based on cutting-edge statistical methods that accommodate some of the unique and previously ignored features of this problem. In fact, recent work supports a highly heterogeneous association between milk production and reproductive performance, whereby heterogeneity is partitioned across several scales and driven by many contributing factors, both physiological and managerial. We conclude that the relationship between milk production and reproductive performance is not necessarily that of a universal homogeneous antagonism and suggest better ways to study and even manage this association. A more comprehensive assessment that draws expertise from multiple scientific disciplines will be required to elicit management recommendations targeted to effectively optimize overall performance of dairy cows and commercial herds.

Received March 23, 2012.

Accepted June 5, 2012.

${ }^{1}$ Corresponding author: nbello@ksu.edu
Key words: milk yield, reproductive performance, management, statistical methodology

\section{INTRODUCTION}

The relationship between milk production and fertility is often perceived as a relatively recent concern but, in fact, it has been ongoing for some time. For instance, a 1929 Minnesota Dairy Bulletin states: "In recent years the opinion has been held by a large number of dairymen that difficulties with breeding accompany high milk production - the conclusion has been drawn that as milk yield has increased during the same interval that the two (i.e., milk yield and fertility) bear the relation of cause and effect" (Eckles, 1929).

Milk yield and reproductive performance are both considered fundamentally important to the economic viability of dairy operations. Remarkably, annual milk yield per cow in the United States has increased from $4,423 \mathrm{~kg}$ in 1970 to $9,333 \mathrm{~kg}$ in 2009 , whereas percentage milk fat and solids-not-fat have remained unchanged (NMPF, 2011), indicating that milk protein and milk fat production per cow have increased at the same rate as fluid milk yield. Many scientific and popular press articles have propounded that innate reproductive performance has deteriorated during the same period. The inference drawn from these trends and more formal studies is that an overall antagonism exists between milk yield and reproductive performance, with deterioration in fertility being perceived as a consequence of increases in milk yield.

In this article, we review and reassess the arguments in favor of a general antagonism between milk production and reproductive performance. Using cutting-edge statistical tools, we attempt to provide new insight into the nature of this association by considering important aspects of the problem that may have been generally misinterpreted or overlooked. We believe the problem is sometimes more complex than what classical statistical analysis available with canned software can accommodate. This article will briefly review some of the previous approaches and their limitations to address 
multiple aspects of the problem. Finally, we describe novel results obtained from statistical methodology specifically developed to overcome some of these limitations and reinvestigate the nature of the association between milk production and reproductive performance accounting for many of its unique and previously ignored features.

\section{GLOBAL DECREASE IN FERTILITY?}

Several reports attest to a historical trend for decreasing dairy fertility (Butler, 1998; Royal et al., 2000; Lucy, 2001). Concurrent trends on milk production per cow indicate yields increasing at a rate of 1 to $2 \%$ per year, based on studies reported in Canada (LeBlanc, 2010), Ireland (Roche et al., 2000), United Kingdom (Royal et al., 2000), Australia (Macmillan et al., 1996), Spain (López-Gatius, 2003), and the United States (Butler, 1998; Lucy, 2001). A common interpretation of these historical trends is that increasing milk yield likely leads to decreasing reproductive performance.

Some recent studies have challenged the perception of a universal antagonism between milk production and reproductive performance by providing evidence that high milk yield may be favorably associated with fertility. That is, higher producing cows have been deemed most likely to become pregnant in some studies (Peters and Pursley, 2002; López-Gatius et al., 2006; LeBlanc, 2010). For example, in cows yielding $>50 \mathrm{~kg}$ of milk per day by 50 DIM, odds of a pregnancy increased by a factor of 6.8 compared with cows producing below that level (López-Gatius et al., 2006). That study also inferred that an increase of $1 \mathrm{~kg}$ in milk yield at peak lactation was associated with an estimated decrease of $1.8 \mathrm{~d}$ in the interval from calving to conception. Similarly, cows with milk production above herd average had greater conception rates (45 vs. $34 \%$ ) compared with lower producing herd mates (Peters and Pursley, 2002). Furthermore, if the herd (rather than the cow) is identified as the experimental unit of performance, favorable production-reproduction associations are also evident such that higher producing herds were determined to have better reproductive performance than lower producing operations (Laben et al., 1982; Löf et al., 2007; LeBlanc, 2010). For example, days open for the highest producing herds were approximately one estrous cycle shorter than days open for low-producing herds (Laben et al., 1982). Similarly, high-yielding herds averaged a 10-d shorter calving interval and had reduced odds of reproductive culling compared with low-yielding herds (Löf et al., 2007).

A recent US Department of Agriculture study suggested partial recovery in dairy fertility since the incorporation of daughter pregnancy rate into bull genetic evaluations, despite no apparent slowing down in the rate of increase of milk production per cow (Norman et al., 2009). In fact, both Holsteins and Jerseys demonstrated increases in reproductive performance after implementation of genetic evaluations for productive life in 1994 and daughter pregnancy rate in 2003 (Norman et al., 2009). It is unclear, however, if incorporation of productive life into genetic selection indices may itself have counteracted the decline in pregnancy rate, as might be expected based on a genetic correlation estimate of -0.59 between days open and productive life (VanRaden et al., 2004). Yet, potential confounding factors (i.e., changing management styles over time) are likely to be partly responsible for the observed plateau or potential rebound in dairy cow fertility, particularly given the relatively small contribution of genetics to the reproductive phenotype, as illustrated by the pervasively low heritability of reproduction traits (Seykora and McDaniel, 1983; Calus et al., 2005; Windig et al., 2006).

\section{GENETIC ANTAGONISM BETWEEN MILK PRODUCTION AND FERTILITY}

Intensive selection for high milk yield is believed to have led to indirect selection for low fertility. Indeed, strong evidence exists for a genetic basis to the antagonism between milk production and reproductive performance (Hansen et al., 1983; Castillo-Juarez et al., 2000; Pryce et al., 2004). For example, estimated genetic correlations between days open and 305-d milk yield ranged between 0.2 and 0.3 (Hansen et al., 1983), whereas that between number of services per conception and fat-corrected milk at 60,180, and $305 \mathrm{~d}$ in milk varied between 0.4 and 0.6 (Berger et al., 1981). Moreover, estimated genetic correlations between firstservice conception rate and mature-equivalent milk yield ranged from -0.3 to -0.4 (Castillo-Juarez et al., 2000).

Although such antagonistic genetic correlations offer a plausible explanation for the historical trends observed, it should also be noted that the genetic information passed on from one generation to the next is only a fraction of the phenotype, namely heritability (Falconer, 1981). Heritability estimates of fertility traits are consistently small across studies, commonly being <5\% (Seykora and McDaniel, 1983; Calus et al., 2005; Windig et al., 2006). In contrast, heritability estimates for production traits range from 20 to $40 \%$ (Seykora and McDaniel, 1983; Castillo-Juarez et al., 2000; Windig et al., 2006). Therefore, despite an antagonistic production-reproduction genetic correlation, the low heritabilities for fertility traits may indicate a relatively minor role of genetics and an overwhelming 
dominance of nongenetic factors on the reproductive phenotype.

Complicating matters further, the genetic correlation between test-day milk yield and fertility traits is estimated to fluctuate during lactation (Berry et al., 2003a,b). Hence, inference based on a particular stage of lactation is of limited scope because it does not necessarily reflect overall reproductive performance over an entire lactation cycle. Similarly, comprehensive lactation cycle measures of reproductive performance (e.g., calving interval) may not necessarily reflect the physiological and managerial circumstances unique to a specific lactation stage of critical interest, particularly first postpartum (PP) insemination.

\section{PHYSIOLOGICAL FACTORS}

From a physiological perspective, there are many factors to consider in the association between milk production and reproductive performance. Recent reviews of the literature on this subject provide comprehensive insight that we do not intend to replicate here. Rather, we highlight main points that are relevant to our discussion and direct the reader to key resources (Morton, 2006; Wiltbank et al., 2006; LeBlanc, 2010) for further information.

One key factor is, arguably, energy balance, which has been proposed to be a mechanistic link between high milk yield and poor reproductive performance (Butler, 2003). Most dairy cows in early lactation experience negative energy balance because of mobilization of adipose tissue, as appetite has yet to peak and DMI does not meet nutrient requirements for lactation (Bauman and Currie, 1980). Subsequent loss of body fat then signals physiological mechanisms in the reproductive endocrine cascade and can lead to perturbed reproductive performance (Lucy, 2003). However, the highest producing cows may not necessarily be those with the most extreme negative energy balance or with the lowest BCS. Rather, the ability of some high-producing cows to promptly maximize DMI after parturition alleviates negative energy balance, even given the required energy demands for high milk production (Lucy et al., 1992). In other words, the risk for anestrus and infertility during the first part of the lactation seems associated with a finely tuned balance between DMI and milk production (Lucy et al., 1992).

Other associations between milk yield and various reproductive processes have been characterized by comparisons between nonlactating virgin heifers or nonlactating cows with lactating cows. For example, lactating cows compared with heifers (Sartori et al., 2002a,b, 2004) have shorter periods of estrus (8.7 vs. $13.8 \mathrm{~h}$ ), greater frequencies of double ovulation (20 vs.
$1 \%$ ) and twinning (8 vs. 15\%), and greater pregnancy losses between d 30 and 60 of gestation (20 vs. 5\%). Furthermore, heifers show greater pregnancy rates $(70$ vs. $35 \%$ ) and greater concentrations of estradiol and progesterone despite having smaller ovulatory follicles (18.5 vs. $14.9 \mathrm{~mm}$ ) and larger corpora lutea (11.1 vs. $7.3 \mathrm{~cm}^{3}$ ) compared with mature cows. Differences in basal liver blood flow between nonlactating and lactating cows suggest greater steroid metabolism in lactating cows as a potential mechanism for reducing circulating concentrations of estradiol and progesterone (Wiltbank et al., 2006).

These differences have been interpreted by many (Knaus, 2009; Oltenacu and Broom, 2010) as implying that lactation is a causative factor for changes in the reproductive physiology of dairy cows despite the observational nature of these studies not directly supporting such claim. That is, without randomization, cause-effect inference is invalid (Fisher, 1926; Casella, 2008). In fact, potential confounders should be considered, including age, DMI, uterine health, PP metabolic diseases, BW, BCS, and energy balance, among others. In other words, misrepresentation of observational data from nonrandomized studies may have driven the conclusion that a universal cause-and-effect relationship exists between milk yield and reproductive processes.

\section{POTENTIAL CONFOUNDING FACTORS}

Concomitant with the historical trends of increasing milk yield and declining fertility are dramatic changes in dairy herd management during the past few decades (Capper et al., 2009). One obvious change is that of fewer commercial dairy operations, each of which concentrates a greater number of cows. That is, the number of US dairy farms decreased from 329,680 in 1980 to 131,509 in 1992 and to 53,127 in 2009, whereas average herd size increased from 19 cows in 1970 to more than 144 cows by 2009 (NMPF, 2011). In 1980, only $4 \%$ of dairy farms were milking more than 100 cows, whereas by $2009,23 \%$ of dairy farms were milking more than 100 cows. In $1980,33 \%$ of the milk was produced on dairy farms of more than 100 cows, whereas in 2009, $83.6 \%$ of milk was produced on farms with more than 100 cows. Furthermore, no dairy herds were milking more than 500 cows in 1980, but by $2009,5.1 \%$ of herds milked 500 or more cows, accounting for almost $60 \%$ of the total milk output in the United States (NMPF, 2011).

It is unclear whether or how adaptations in management and management effects have changed monotonically relative to the increase in size of dairy operations. Although, to our knowledge, no data are readily available, it seems likely that the average number of cows 
managed per employee has increased. Moreover, the labor force has changed culturally from predominantly immigrant Americanized Europeans to predominantly Hispanics. Currently, Hispanic employees (of which approximately $63 \%$ are Mexican) represent approximately $75 \%$ of the hired labor force on dairy farms in California (Tranel and Derdzinski, 2010).

Further management changes in recent decades include greater usage of confinement housing, whereby cows are housed almost exclusively on concrete after first calving. Diet composition has also changed from a mainly roughage diet to a diet that contains more concentrates than forage. On-farm delivery of this diet is more frequently based on precision feeding systems. Breeding strategies have moved from natural service to an overwhelming prevalence of AI and ovulation synchronization programs (Caraviello et al., 2006; Miller et al., 2007). Use of bST has also waxed and waned since it first became publicly available in the United States in 1994 (Caraviello et al., 2006; Capper et al., 2008). On-farm implementation of computers for electronic filing and tracking of individual cows is not an option but rather a managerial necessity for modern farmers. Current use of computerized technology has expanded even further to include diet formulation software, automatic sorting systems, and robotic milking, among others. Clearly, many management practices have changed on dairy farms during the past 30 to $40 \mathrm{yr}$ and may confound any inferences on an antagonism between production and reproduction based on historical trends in milk yield increases and declines in fertility.

\section{MEASURES OF MILK YIELD AND REPRODUCTIVE PERFORMANCE}

The specific definitions of various measures of milk production and reproductive performance need to be carefully considered to better interpret the nature of their association. Component-corrected milk yields should be most appropriate as they account for most of the energy content in fluid milk. Short-term yields may be useful when testing the immediate influence of milk production at or near the time of first PP inseminations, but may not be reliable for estimating total lactation performance as supported by an estimated phenotypic correlation of just 0.36 between 50 -d and 305-d milk yield (Mayeres et al., 2004). Conversely, actual 305-d yields more accurately reflect the entire lactation, but may not accurately assess the metabolic environment during the actual breeding period. For instance, actual 305-d yields are likely not representative of inherent differences in metabolic needs of first-lactation cows that are still growing yet may be producing milk at the same level as older cows with no growth require- ment and greater yields. Age-adjusted or 305-d matureequivalent records adjust not only for parity but also for differences in milking frequency, breed, age at calving, month of calving, duration of lactation, and region of the country. Yet, potential confounders for this adjustment might include breed and nutritional management. Lower yielding cows in pasture-based systems have a different metabolic status than full-fed cows housed in confinement. Considerations of what is high, moderate, or low production must be defined within a given production system and genetic background, and these effects should be accounted for in any formal analysis.

Beyond the issue of time scale, different candidate measures of reproductive performance pose additional challenges to clearly define the matter. Historically, genetic studies have been based on measures that are readily available from dairy record processing centers, including conception rate, number of services per conception, days open, and calving interval. Each of these variables is strongly influenced by management practices that may thwart insights into potential biological phenomena. For example, days open and calving interval can be substantially affected by the duration of the voluntary waiting period, by DIM to culling, or by designating nonpregnant cows as "do not breed." Furthermore, conception rate varies depending on the DIM when insemination occurs, whether after detected estrus (Britt, 1975) or timed AI (Tenhagen et al., 2003). In addition, estrus-detection rate, and thus pregnancy rate, may vary according to variously applied estrusdetection devices, including heat mount patches, radiotelemetric rump-mounted pressure sensors, or other activity monitors (Stevenson, 2001).

\section{CAUSAL VERSUS ASSOCIATIVE INFERENCES}

Following a review of studies on the association between milk production and reproductive performance, Morton (2006) highlighted some of their key weaknesses, including some already mentioned. Specifically, he concluded that (1) many studies ignored other variables that have changed concurrently with production and reproduction, thus leaving inference on their association susceptible to confounding, and (2) biases likely exist in the apparent production-reproduction association because of the impact of potential herd-specific managerial decisions on the timing of first insemination as a function of milk production that may not have been taken into account.

At this point, we find it useful to reflect upon some basic principles of experimental design and analysis, as developed by Sir Ronald A. Fisher (Fisher, 1926), regarding the nature of scientific inference actually supported by research data. The relationship between milk 
production and reproductive performance has been studied using observational data but not randomized studies. That is, cows are not randomly assigned to a pregnant or nonpregnant category to study a response such as milk yield; neither are cows routinely assigned at random to a given level of milk production to study pregnancy success. Rather, milk yield and reproductive status are jointly recorded as existing conditions on individual cows such that any measure of association (i.e., correlation) between them is not to be interpreted as a cause-effect relationship. In the absence of randomization, any correlation between 2 traits may be due to a direct effect of trait 1 on trait 2 (or trait 2 on trait 1) or to other extraneous variable(s), either known or unknown, that jointly affect(s) both traits. Although it is possible to account for some confounders using known explanatory covariates, others may be uncontrollable and sometimes even unknown. Only randomization effectively breaks this potential confounding by distributing their effects throughout the experiment. Randomization thus provides an even playing field on which to compare treatments of interest in such a way that their effects can be reliably estimated and are reproducible. In the dairy sciences, one may argue that unavoidable logistical limitations force such observational research in lieu of experimental studies, yet the inherent lack of randomization for milk yield and reproduction data precludes any cause-and-effect inference as inherently inappropriate, at least based on traditional modeling approaches.

Randomization has important statistical implications, not the least of which is reproducibility of inferences on the behavior of complex systems and mitigation of the potential effects of external interventions. Without appropriate randomization, it becomes extremely difficult, if at all possible, to effectively eliminate systematic bias with reasonable probability, particularly those biases resulting from latent confounders that might influence conclusions and interpretations of data analyses. The process of randomly assigning experimental units to treatments is still one of the most fundamental principles of experimental design and inference (Casella, 2008).

Alternatively, methods are available that attempt to eliminate or attenuate biases and confounders from observational studies. Typically, multiple phenotypic traits are recorded during an observational study. One may argue that each of these traits is not necessarily an isolated outcome from a complex system. Rather, a biological system may exhibit mutual interrelationship among its variables, including potentially recursiveness and feedback (Gianola and Sorensen, 2004). In dairy production systems, one may consider a phenotypic network that connects not only milk yield and repro- ductive performance, but also other traits such as udder health, incidence of metabolic or infectious diseases, and nutritional status. Recently, structural equation models (StEM) have been proposed to study causal phenotypic networks among traits in a multivariate system for observational studies (Wu et al., 2010; Rosa et al., 2011). With StEM, one trait may be treated simultaneously both as a response and as a predictor for another trait, thus accounting for recursiveness and feedback between both traits and providing a potential functional (causal) link between them. One may then infer phenotypic networks describing such functional interrelationships among traits; also, competing networks may be compared using model selection criteria to decide upon a causal structure that is best supported by the data. Structural equation models have been used to study functional interrelationship between phenotypes in several animal agricultural settings, including dairy cattle (de los Campos et al., 2006b, König et al., 2008; de Maturana et al., 2010), pigs (Varona et al., 2007), and dairy goats (de los Campos et al., 2006a). In animal breeding and genetics, recent articles highlight methods developed either to account for confounding genetic effects (Valente et al., 2010) or to exploit the notion of Mendelian randomization and the directional effect from genes (DNA polymorphisms) to phenotypes (Neto et al., 2010) to infer phenotypic networks and causal effects among traits.

As they further evolve and refine, StEM constitute a promising technique for the functional characterization of phenotypic networks. This has important implications for our understanding and management of multivariate biological systems, particularly in situations where direct experimentation is logistically or ethically impossible and thus, observational studies are unavoidable.

\section{HERD-LEVEL VERSUS COW-LEVEL ASSOCIATIONS}

An additional conclusion from the review of studies by Morton (2006) on the association between milk production and reproductive performance was that inferences on associations at the individual (i.e., cow) level may be confounded with inferences on associations at the aggregate (i.e., herd) population level. Ecological fallacy (Robinson, 1950; Greenland and Robins, 1994) is a term used to define this latter problem based on the false premise that relationships observed for groups necessarily hold for individuals. As shown empirically by Robinson (1950), there needs to be no such correspondence; in fact, correlations between traits at the individual level and correlations between traits at the aggregated group level do not even need to share the same sign! Additional considerations to keep in mind 
when considering ecological fallacies include confounding and uncontrolled nonlinearities, as well as measurement error (Greenland and Robins, 1994), all of which further complicate the issue.

Direct implications arise from interpreting ecological fallacies in the context of dairy production systems. For example, Calus et al. (2005) observed discrepancies between trends at the level of individual cows compared with those at the aggregate herd level when studying the relationship between udder health and milk production. Herds with higher average protein production had considerably less mastitis and lower SCS than lower production herds (Calus et al., 2005). This finding conflicts with evidence that higher yielding cows are also at increased risk for mastitis (Lund et al., 1999; Ingvartsen et al., 2003). As a plausible explanation for this apparent contradiction, Calus et al. (2005) proposed that high-producing herds might have management strategies in place to control average SCC. In contrast, cows with the highest production may still be at greater risk of mastitis within each herd. So, even though high-producing herds may better manage for average SCC, an antagonistic relationship at the cow level might still exist between production level and risk for mastitis within herds.

In the context of milk production and reproductive efficiency, the relationship between herds may differ from that within herds as well. For example, Laben et al. (1982) described enhanced reproductive performance in herds with greater average milk yields, whereas the opposite relationship was observed for individual cows within those same herds. Therefore, despite general historical trends of reproduction being unfavorably associated with milk production, it is not necessarily true that higher producing herds have greater difficulty in getting cows pregnant.

Two competing questions should be posed at this point: (1) has the inherent capacity of cows to become pregnant actually decreased over time because of increasing milk yields or (2) has the human capacity to manage the metabolic, nutritional, housing, and social needs of increasingly more productive dairy cows been challenged (LeBlanc, 2010)? As pointed out by LeBlanc (2010), "it is important to separate the biology of reproductive function from the effects of economically-based management decisions about culling and continuation of breeding." Most realize the inherent confounding between physiological and managerial decisions, whereby the most productive cows are more likely to be inseminated longer and less likely to be culled. The opposite is also true - that less productive cows are less likely to be inseminated longer and more likely to be removed from the herd.
Ignoring the hierarchical structure of dairy data is an often-unappreciated phenomenon in previous studies on the association between milk production and reproductive performance. This hierarchy refers to the fact that cows are managed (i.e., clustered) within herds and thus subjected to common management decisions that are specific to a given herd but that may be quite diverse across herds. That is, cows in a given herd would more likely share a similar production environment. It follows from this hierarchy that one might choose to focus on the dairy herd as a business entity for herdlevel inference, or, alternatively, on the dairy cow as a physiological unit of performance, thus defining a cowlevel scale for inference.

In most cases, scientific studies on the productionreproduction association are based on data collected at both the cow and herd levels and then brought together in such a way that it is impossible for the reader to differentiate between the traits at the 2 different levels. These distinctions are vitally important. For example, an individual cow may be characterized as pregnant or not pregnant (i.e., thus defining a 0/1 binary outcome) with a certain probability that may depend on several factors including parity, BCS, DIM, and health status. In turn, herds would be characterized by conception rates (binomial outcomes), which are usually obtained as a combination of pregnancy outcomes from different groups of individual cows, each herd having a different size and different probability of successful pregnancy. One might assume that pregnancy outcome of a cow and conception rate of a herd are equivalent measures of reproductive performance and hence correlate in virtually identical ways to milk production expressed at the cow and herd levels, respectively. This is, however, the misconception of ecological fallacy described previously. In other words, cow-level and herd-level data comprise 2 different sources of (co)variability that intertwine with each other to yield an overall phenotype. Whatever associations are established at the herd level may not necessarily hold at the individual cow level, and vice versa (Windig et al., 2005; Bello et al., 2010, 2012b). Indeed, based on data from 53 herds, Windig et al. (2005) demonstrated empirically that the estimated overall correlation between milk production and fertility differed considerably from correlation estimates that were computed within individual herds; that is, at the cow level. Hence, disregarding herd clustering in the analyses led to conclusions obtained within herds that were contradictory to conclusions obtained across the entire data set. This result was puzzling to the authors, although it may be partially explained by the concept of ecological fallacy. 
To illustrate the distinctions of cow-level versus herdlevel associations, we conducted a data simulation to demonstrate some of the practical inferential implications of the relationship between reproductive efficiency and milk production being of opposite signs for cows and for herds. In a simulation setting, one knows and has full control over the true data generation processes. Therefore, the "truth" is known and a reference benchmark is available for objective evaluation of the net outcome resulting from multiple complex mechanisms and contributing effects. Moreover, the condition of "known truth" in simulation studies also allows assessment of the performance of the proposed statistical methods used for inference, thereby circumventing any "black box"-type concerns on the methodology.

For this simulation, we generated data on calving interval and 305-d milk yields (305MY) for 200 cows within each of 200 hypothetical herds for a total of 40,000 cows. For the purpose of illustration, suppose that the production-reproduction association was favorable across herds (i.e., herd level), whereas it was unfavorable within herds (i.e., cow level). We note that this data simulation is only intended to demonstrate how one might go about detecting differences in associations between the 2 traits at 2 different hierarchical levels, namely cow-level and herd-level. That is, this simulation does not make any claim as to the true biological association at either level, but rather illustrates how to infer them. Input values (means and standard deviations) specified for this data simulation were obtained from DHIA records for Michigan during 2006. An unfavorable cow-level association between $305 \mathrm{MY}$ and calving interval was simulated using a positive within-herd correlation coefficient, $r_{\text {cow }}=0.5$. That is, cows simulated to have greater (standardized) milk production during their lactation were also cows that took longer to become pregnant. In turn, a favorable herd-level association between 305MY and calving interval was simulated using a negative between-herd correlation, $r_{\text {herd }}=-0.6$. In other words, simulated herds of greater average milk yields were also herds with shorter average calving intervals.

Figure 1 illustrates the simulated data with a scatterplot of calving interval (y-axis) over 305MY (x-axis) for all 40,000 simulated cows $(200$ cows per herd $\times 200$ herds) without any regard for distinguishing between cow or herd levels in the data. The overall correlation among calving interval and 305MY for all 40,000 cows regardless of herd clustering was estimated to be $\hat{r}_{\text {overall }}$ $=0.16$. Note that this estimate does not approach either of the true correlations of $r_{\text {cow }}=0.5$ or $r_{\text {herd }}=-0.6$ specified in the data simulation. Rather, the estimated $\hat{r}_{\text {overall }}$ is a design-dependent (number of cows per herd and number of herds) function of the 2 correlations describing relationships between the 2 traits at 2 different levels. The meaning and implications of the estimated $\hat{r}_{\text {overall }}$, whether for individual cows or for farming business units, is then unclear.

Figures $2 \mathrm{~A}$ and $2 \mathrm{~B}$ show scatterplots that illustrate and correctly dissect the cow-level and herd-level scales of the problem that are hidden from Figure 1, thus illustrating the error of ecological fallacy. Figure 2A illustrates the association between calving interval and $305 \mathrm{MY}$ within 3 arbitrarily selected herds; that is, at the cow level for those selected herds. Figure 2A also shows the estimated cow-level correlation coefficients within such herds (i.e., herd 1: $\hat{r}_{\text {cow }}=0.46$; herd 2: $\hat{r}_{\text {cow }}$ $=0.56$; herd 150: $\left.\hat{r}_{\text {cow }}=0.41\right)$, which seem to match, within sampling error, the true value of the cow-level correlation used to simulate the data (i.e., $r_{\text {cow }}=0.50$ ). In turn, Figure 2B illustrates the herd-level association based on a scatterplot of the average calving interval and average $305 \mathrm{MY}$ for each of the 200 simulated herds. The estimated correlation coefficient between average herd performances $\left(\hat{r}_{\text {herd }}=-0.63\right)$ also closely matches, again within sampling error, the true value of the herdlevel correlation used to simulate the data $\left(r_{\text {herd }}=\right.$ -0.60). In summary, even though it is plausible that a cow-level correlation between milk yield and reproduction may be opposite in direction to that of a herdlevel correlation, neither trend would be apparent from a data analysis unless the cow and herd scales in the data were appropriately dissected. Without this distinction in previous data analyses, differences in the relative proportions of cow-level and herd-level information may explain a considerable amount of the observed ecological fallacy inconsistencies among several studies. Hierarchical linear models can be used to readily accommodate the 2 different levels of correlation by modeling herd effects for both traits as correlated random effects in a bivariate mixed model (Bello et al., 2010).

Now, specifying the linear model with herds as random effects rather than as fixed effects additionally implies broadening of the inferential space (McLean et al., 1991; Tempelman, 2009). A broad scope of inference is constructed such that hypothesis tests on, say, any treatment effects apply not only to the herds specifically involved in the data analysis, but also to the populations of all herds from which these study herds are presumably representative (McLean et al., 1991; Tempelman, 2009). Despite this being the general intent of most dairy science researchers, failure to specify herds as random effects does not allow such an interpretation. Furthermore, most studies are conducted on a single (or few) herd(s), thus providing little, if any, 


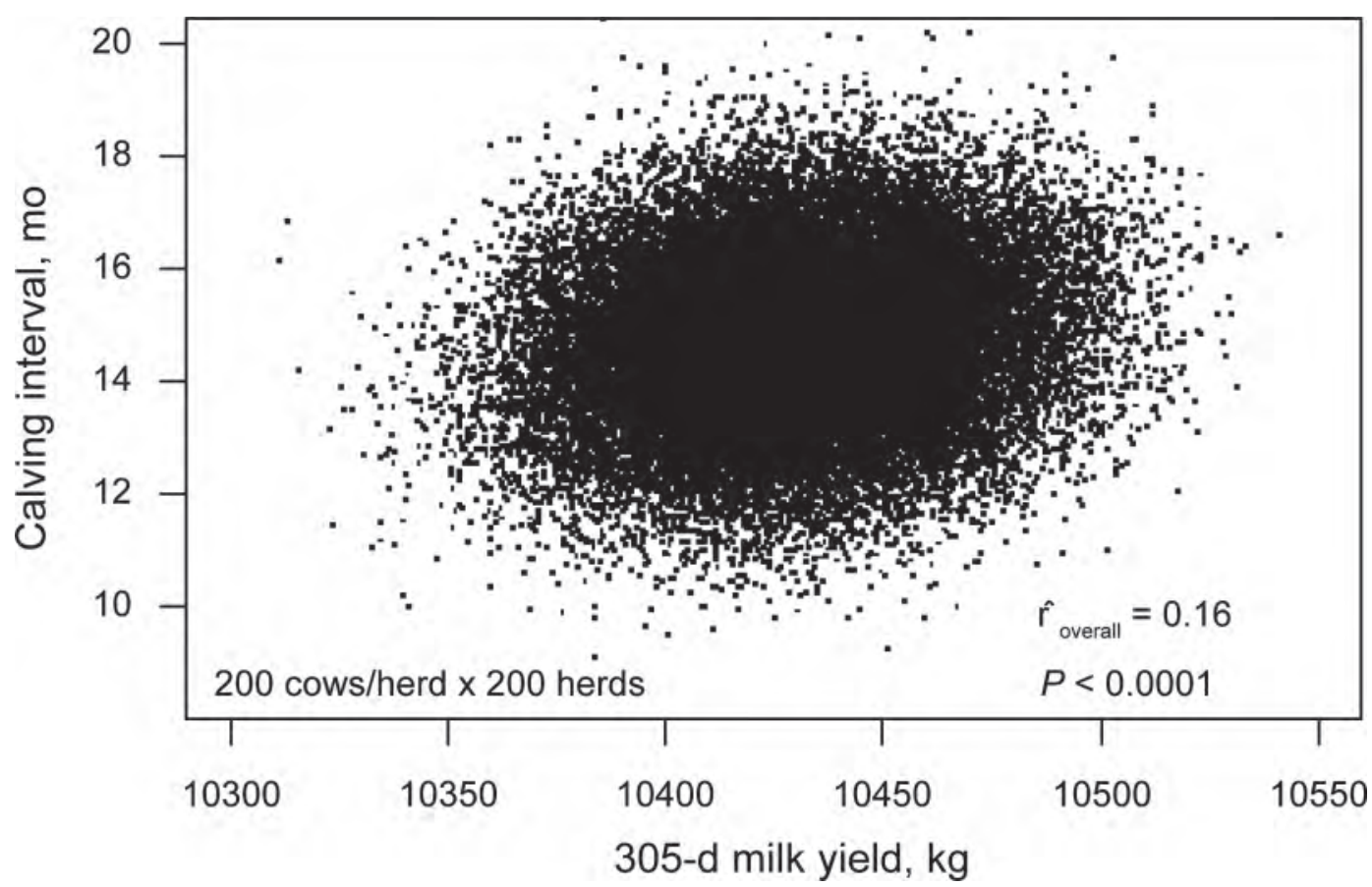

Figure 1. Scatterplot of simulated data for calving interval (y-axis) and 305-d milk yield (x-axis) on 40,000 cows, corresponding to 200 herds with 200 cows per herd. The scatterplot illustrates the overall association between performance outcomes but it does not consider the hierarchical cow-level and herd-level structure of the data. The estimate of the overall Pearson correlation coefficient, namely $\hat{r}_{\text {overall }}$, and its corresponding $P$-value are shown.

true replication for inference on herd-level associations. Arguably, single-herd studies may be valuable for assessing focused biological (proof of concept) hypotheses under intensive conditions of data collection. Nevertheless, the inferential scope of single-herd studies is strictly limited to that single herd; that is, the scope of inference is narrow (McLean et al., 1991; Tempelman, 2009). In other words, not much can be claimed about associations in other herds.

In quantitative genetics studies, multiple-herd studies are common but herds are often specified as fixed rather than as random effects using the definition of "contemporary groups" (CG) or herd-year-seasons (Kadarmideen et al., 2003; Tsuruta et al., 2004). Although modeling herds or clusters as fixed effects in these analyses accounts for differences between herds, the resulting hypothesis test on treatment effects is then only based on the cow-to-cow variability within the study herds such that the scope of inference is strictly narrowed to only those herds in the study (McLean et al., 1991; Tempelman, 2009), regardless of the number of cows involved. In these same analyses, the error degrees of freedom can be grossly overstated when some treatments are used exclusively, or almost exclusively, within certain herds or CG, such that herds are often almost experimental units themselves. Analyses of such data may require formal inference on the degrees of freedom itself using Satterthwaite's approximation (Littell et al., 2006; Tempelman, 2009). Again, these issues are completely ignored in data analyses treating herd effects as fixed, thereby wreaking havoc with the reproducibility of conclusions across studies. That is, narrow-scope inferences represent "local truths" (Richter et al., 2009) that only validate for the specific environment in which the original experiment was conducted (Tempelman, 2009).

Reproducibility of research results defines the very core of modern research integrity. Yet, the inability to reproduce research results seems quite prevalent and has recently received considerable attention, including the general media (Naik, 2011; Young and Karr, 2011). Indeed, the leading scientific journal Science dedicated a substantial portion of its December 2, 2011, issue to the problem of data replication and reproducibility in various scientific disciplines (Jasny et al., 2011). In the context of dairy science research, for instance, an experiment carefully conducted within a research herd may not reflect management conditions representative of the overall dairy industry for which the study inferences are intended. Modeling herds or CG as random effects allows any resulting inferences on treatment effects or risk factors to better generalize to the dairy population of interest (Tempelman, 2009). Moreover, an appropriate modeling of the cow-herd hierarchy is 


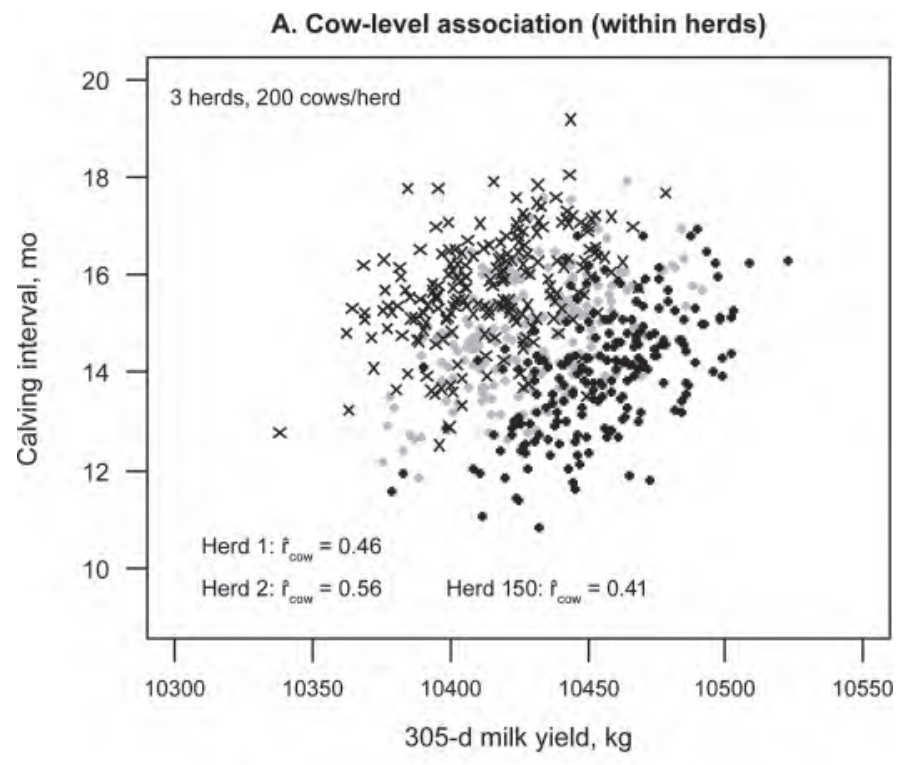

B. Herd-level association (between herds)

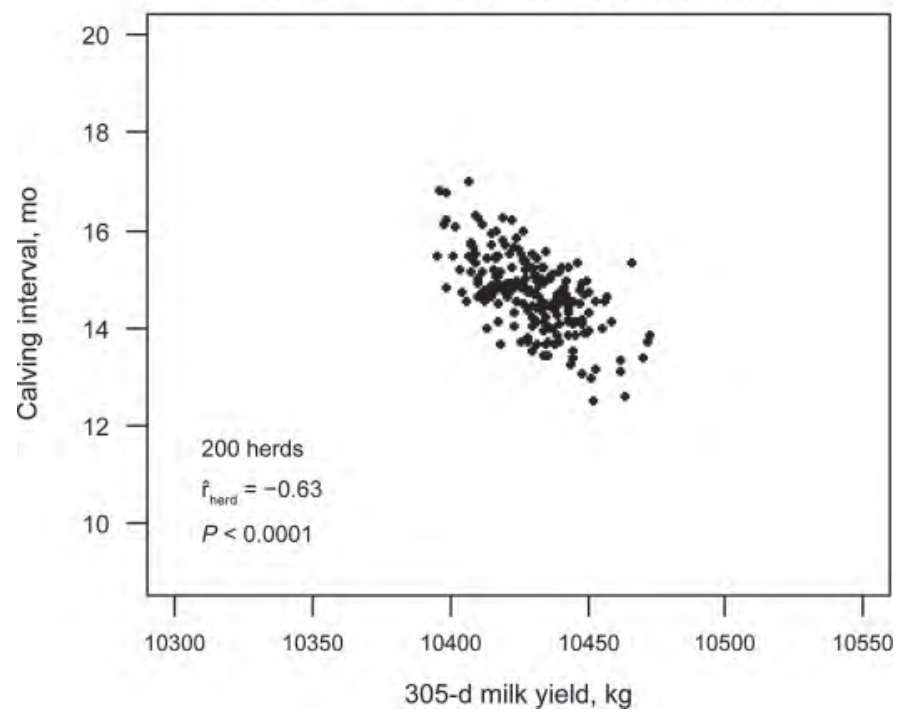

Figure 2. Scatterplot of simulated data for calving interval (y-axis) and 305-d milk yield (x-axis) illustrating (A) the cow-level (withinherd) association between performance outcomes for 3 arbitrarily selected herds (gray circles, herd 1; solid black circles, herd $2 ; \times$ herd 150), and (B) the herd-level association between performance outcomes based on herd averages for each outcome. The corresponding cow-level and herd-level estimated Pearson correlation coefficients are provided in (A) as $\hat{r}_{\text {cow }}$, and in (B) as $\hat{r}_{\text {herd }}$.

critical to disentangling the multilevel correlation between traits, thus facilitating a better understanding of the involved complex biological and environmental management systems.

Despite their higher cost and logistical complexity, interdisciplinary multi-location multi-herd experiments that target broad inference may be the most efficient allocation of research funding due to the possibility of
1) generalizing inference of treatment effects, and 2) estimating multi-trait correlations between important traits beyond the experimental sample to the entire population of dairy herds. Concerted efforts of multiple research institutions and commercial entities, as well as professionals from various areas of expertise, supported by federal and industry-based funding sources, will be likely required to successfully achieve these goals.

\section{OTHER STATISTICAL PITFALLS}

Some previous reports that have inferred upon the production-reproduction association are afflicted by an additional limitation; namely, their univariate (i.e., single trait response) data analysis approach. In univariate analyses, one trait is modeled as a function of the other, whether reproductive traits as a function of milk yield (Spalding et al., 1974; Laben et al., 1982; López-Gatius et al., 2006) or milk yield as a function of fertility (Windig et al., 2005; López-Gatius et al., 2006). By so doing, one must assume that whatever trait is chosen to be the explanatory variable is measured without error and not influenced by any other covariates in the model. The latter assumption is particularly dubious because both milk production and reproductive performance are known to be influenced by multiple factors (e.g., physiological, managerial, and genetic). Joint modeling of 2 (or more) traits using multivariate (i.e., multiple-trait model) analysis techniques constitutes a potential solution to this problem, with the added advantage that the modeled correlation between traits can be used to sharpen inference on each of the analyzed traits (Sørensen et al., 2003; Riley et al., 2007). A recent simulation study compared the inferential efficiency of bivariate (2-trait) models with that of a univariate model where one trait was modeled as a function of the other (Cardoso et al., 2008). Even with moderate correlation values, bivariate analyses afforded substantial gains in statistical power and greater precision for detecting effects of interest in a given trait than the counterpart univariate analyses (Cardoso et al., 2008). In fact, modeling one trait as a function of the other was considered by the authors to be an "inappropriate analysis method" because it actually led to incorrect inferences.

An additional concern is the typically censored nature of various measures of reproductive performance and the potential biasing effects that censoring can have on inference if ignored. This concern can be addressed in the context of a missing data framework (Little and Rubin, 2002). Indeed, for cows that fail to become pregnant during a lactation cycle, only partial information is available regarding their reproductive performance; all that is known is that the actual number of days 
open (or functions thereof, such as calving interval) exceeds an observed time to reproductive culling. Data analyses should take into account this censoring process to avoid biased inferences, particularly because the pattern of data missingness (i.e., censoring due to reproductive culling) is not necessarily random (Little and Rubin, 2002, p. 17) but is dependent upon herdspecific management factors. A possible approach to overcome this problem is by joint bivariate modeling of the censored reproductive outcome along with another uncensored production outcome for which complete information is available. When both outcomes are correlated, it is possible to borrow missing information for the censored trait from the other uncensored trait with complete information, within each subject-specific pair of responses. Indeed, bivariate linear mixed models using complete data on one trait has proven to be an efficient way to recover information that was missing in a nonrandom pattern for the other trait (Cardoso et al., 2008). That is, bivariate modeling having complete data on one trait combined with any pattern of missingness on the other renders this a nonproblem (Little and Rubin, 2002, p. 332-337).

Hence, formal approaches to multivariate (i.e., multiple trait) analyses that account for censoring are required to better understand how to jointly optimize milk yield and reproduction in dairy cows.

\section{HOMOGENEOUS OR HETEROGENEOUS ASSOCIATIONS?}

As suggested earlier, a multivariate mixed model analysis can separately model herd- and cow-level associations between multiple traits. However, conventional approaches to this analysis assume homogeneity of variances and covariances across all herds and across all cows within a herd. That is, the cow-level and herdlevel associations between traits are assumed to be homogeneous across all cows and herds, respectively.

Even though the relationship between milk production and reproductive performance may be antagonistic on average, studies indicate that this association may be far from homogeneous across environments. In fact, the production-reproduction association reportedly varies from herd to herd (Windig et al., 2005, 2006) with a magnitude that depends upon the specific herd environment (Castillo-Juarez et al., 2000; Windig et al., 2006). For example, Windig et al. (2005) showed empirically that the estimated within-herd (i.e., cowlevel) correlation between milk production and fertility fluctuated widely from strongly negative to strongly positive values among the 53 herds in their study. Hence, further extensions to multivariate mixed models are needed to explicitly accommodate heterogeneous cow-level associations either between herds or as a function of specific management practices to avoid inferential distortions resulting from potentially tenuous assumptions of homogeneity. Similarly, the association among herds may differ among groups of herds defined by some characteristic, such as geographical region or implementation of a given management practice. Identifying factors that mitigate (or even counteract) the antagonism between milk yield and fertility would be of substantial interest to the dairy industry.

Multivariate hierarchical Bayesian models present a general framework and a viable alternative to comprehensively address this problem (O'Hagan, 2004) because of the embedded hierarchical rationality of the Bayes paradigm, its direct inferential approach, and its intuitive interpretation (Sorensen and Gianola, 2002). Furthermore, inference based on these models is readily accommodated by the recent development of powerful computational tools such as simulation intensive Markov chain Monte Carlo techniques (Gilks et al., 1996).

We have recently developed and validated statistical methodology that addresses the unique features and complexities on the nature of the production-reproduction association through hierarchical Bayesian extensions to classical bivariate linear mixed modeling of residual (cow-level) and random effect (herd-level) (co)variances for the joint analysis of 2 continuous response variables (Bello et al., 2010). This approach involves modeling heterogeneous associations between outcomes using dispersion parameters generated from a square-root-free Cholesky reparameterization of (co)variances (Pourahmadi, 1999). That is, the proposed hierarchical Bayesian approach specifies a linear mixed model not only directly on the data itself, as is the case to classically model treatment effects, but also on the dispersion parameters defined at both the cow and herd levels. We further extended this approach to bivariate generalized linear models (Bello et al., 2012b) and thus, to model heterogeneous associations between a continuous and a categorical outcome, such as health and reproductive fitness. Implementation of the proposed bivariate hierarchical Bayesian models is based on Markov chain Monte Carlo, a tool that provides unprecedented flexibility to appropriately model highly hierarchical model structures. These recent methodological developments, combined with the conflicting evidence on the association between milk production and reproductive performance of dairy cows, are timely when revisiting the nature of the relationship between production and reproduction from a comprehensive interdisciplinary perspective.

Our working hypothesis was that the cow-level and the herd-level associations between milk production and reproductive performance of dairy cows are het- 
erogeneous and depend upon management practices and herd attributes. To address this hypothesis, the statistical models were applied to large data sets ( $>120,000$ lactation records) from more than 500 commercial dairy farms in Michigan. For specific details, refer to Bello et al. (2012a). In particular, 305MY and calving interval were selected as comprehensive (i.e., lactation-encompassing) measures of production and reproductive performance. A second analysis focused on the relationship at a more specific lactational stage; that is, between milk yield at and pregnancy outcome to first PP insemination when daily yield is at or near its peak and fertility is first tested (Bello, 2010). Each pair of responses, namely, $305 \mathrm{MY}$ and calving interval, as well as milk yield at and pregnancy outcome to first $\mathrm{PP}$ insemination, was jointly fitted using the previously developed bivariate hierarchical Bayesian models (Bello et al., 2010, 2012b). Means, variances, and covariances between measures of milk production and reproductive performance at both cow and herd levels were jointly modeled as separate functions of management practices and herd attributes. Deciding which of these factors were to be incorporated as explanatory variables on what parameters and at what level of the hierarchical model was based on a sequential model selection procedure using the deviance information criteria (Spiegelhalter et al., 2002).

Evidence for heterogeneity in the association between milk production and reproductive performance was overwhelming, particularly between 305MY and calving interval, and, to a lesser extent, between milk yield and pregnancy success at first PP insemination (Bello, 2010; Bello et al., 2012a). Most notably, inferred relationships were generally quite different and, in some cases, opposite in sign between the cow-level and the herd-level components. Second, management practices and herd attributes were identified as key contributors to this heterogeneity. In particular, intensive management conditions seemed to contribute to a more favorable association in some cases, or to a partial alleviation of an overall antagonism in others. A selection of the more interesting results (Bello, 2010; Bello et al., 2012a) follows.

At the herd level, herds using bST extensively $(>50 \%$ of their cows) had a favorable association between milk production and reproductive performance across the entire lactation, with an estimated decrease in herd calving interval of $1.37 \pm 0.13 \mathrm{~d}$ per $100-\mathrm{kg}$ increase in herd 305MY. In contrast, at the cow level, higher producing cows had overall poorer reproductive performance than lower producing cows within herds. In fact, calving interval increased by $0.51 \pm 0.01 \mathrm{~d}$ per $100-\mathrm{kg}$ increase in cow $305 \mathrm{MY}$. This antagonism was partially mitigated if cows were milked thrice daily or greater
$(0.45 \pm 0.01 \mathrm{~d}$ per $100 \mathrm{~kg})$ compared with twice-daily milking $(0.57 \pm 0.01$ per $100 \mathrm{~kg})$.

Our analyses also demonstrated that within herds, at the cow level, milk yield and pregnancy outcome at first PP insemination were not apparently linked to each other; that is, the association coefficient was not significantly different from zero. In contrast, at the herd level, the relationship between milk yield and pregnancy outcome at first PP insemination was antagonistic and dependent on management practices determining a baseline level of fertility for the herd. Hence, herds with greater milk yield at the time of first PP insemination showed impaired pregnancy rates to first insemination; however, within such herds, cows with greater yield were not determined to be any more or less likely to become pregnant than lower yielding herd mates.

As anticipated previously in the simulation study and confirmed by our analyses, conclusions on the association between milk production and reproductive performance at the cow level do not necessarily mirror those at the herd level. Furthermore, inferences based on whole-lactation measures need not align with snapshot inferences on the association between production and reproductive performance restricted to first PP insemination. That is, one may expect that the mechanisms underlying short-term responses during the critical period of peak lactation at which first PP insemination occurs may not necessarily be the same as those over a longer period (i.e., during the entire lactation cycle).

Of particular interest was the random effect of herdyear clusters (i.e., CG), which turned out to be, by far, the greatest contributor to heterogeneity in the cowlevel association between 305MY and calving interval. Similarly, Michigan counties differed significantly in the magnitude of the herd-level association between milk yield and pregnancy outcome at first PP insemination. Taken together, these results support further investigation of regional environmental conditions and herd management practices as sources of heterogeneity that might be further characterized to help partially alleviate an antagonism or enhance a favorable relationship between milk production and reproductive performance in both individual dairy cows and across commercial herds.

\section{WHERE DO WE GO FROM HERE?}

The simultaneous optimization of both milk yield and reproductive performance of dairy cows is vital to the profitability and sustainability of the dairy industry. Despite the common belief of an overall antagonism between milk yield and fertility, we have provided evidence that this relationship is more complex than previously 
thought. In this article, we reevaluate the evidence supporting the belief of a universal antagonism and discuss the multiple shortcomings of the statistical methodologies commonly implemented in previous studies. These shortcomings include causal inference inappropriately driven by observational data and inadequate statistical analysis methods, experimental design and statistical modeling restricted to narrow scope of inference, singletrait analyses that specify milk yield or reproduction as explanatory covariates for the other trait instead of multiple trait analyses that recognize both traits as response variables, and a general underappreciation of cows and herds as separate, yet hierarchically interconnected units of performance. In addition, most data analyses have assumed a homogeneous association between milk yield and reproductive performance despite the immense diversity of environmental conditions under which cows are managed.

Coupling a critical review of the literature with novel cutting-edge hierarchical Bayesian statistical tools to address the aforementioned concerns, we conclude that the concept of "one-size-fits-all" is too simplistic to describe the nature of the association between milk production and reproductive performance of dairy cows. That is, these associations are not only different at the cow and herd levels, but they are also heterogeneous across herds and functions of management factors as substantiated by our recent work.

The hierarchical aspect of this problem is such that cow-level and herd-level components represent delicate intricacies between a cow's physiology and the management and business decisions of the production system (i.e., herd) in which that cow performs. Furthermore, these hierarchical components do not necessarily mirror each other. Indeed, the failure to recognize this cow-herd duality can easily mislead one into ecological fallacies, partially explaining the dissenting evidence on this subject. One also may consider augmenting our previous work with a third scale by dissecting the cowlevel component into its genetic and nongenetic contributions (Berry et al., 2003b; Tsuruta et al., 2009). The integration of genetics and management (i.e., environment) into a comprehensive plan for simultaneously improving milk yield and dairy fertility certainly looks to be promising, especially as the era of genomic selection unfolds (Veerkamp and Beerda, 2007). Indeed, accounting for genetic and nongenetic components of the cow-level correlation between production and reproduction should enable selection of appropriate genes to jointly optimize both traits.

Second, our multifactorial inferences on the production-reproduction association argues for the recognition of management practices and herd attributes as key contributors to this association at both the herd and cow levels. These results indicate that the link between milk production and reproductive performance may be partially manageable and potentially altered or optimized in a somewhat targeted fashion. More research is needed to ascertain management scenarios under which milk production and reproductive performance of dairy cows could be jointly optimized. For instance, it might be desirable to investigate interactions between fixed effects (i.e., management practices) as potential sources of heterogeneity in the production-reproduction association at both levels. As an example, one might be interested in assessing whether the effect of milking frequency on the cow-level association differs between primiparous and multiparous cows, thus allowing for management strategies tailored to each group. Our work also indicated that a more favorable production-reproduction association was detected under highly specialized management practices, such as more frequent milking and adaptation of new technologies to enhance efficiency of milk production. These types of conditions typically characterize intensive production systems. Intensive production management practices have also been identified as important for enhancing business profitability and technical efficiency (Cabrera et al., 2010), for promoting environmental sustainability (Capper et al., 2008, 2009) and for meeting food supply challenges of the century (Simmons, 2009).

At this point, however, a note of caution cannot be overemphasized: cause-and-effect inference from observational data is extremely complex and requires very specific statistical methods. Many statisticians maintain that only randomized experiments allow for causal inference (e.g., Fisher, 1926; Casella, 2008); others believe that much more than symmetric associations (i.e., correlations and covariances) can be learned from observational studies (e.g., Shipley, 2002; Pearl, 2009; Rosenbaum, 2010). In the context of dairy production systems, randomization-driven cause-effect inference would imply, for example, being able to randomly assign herds, and even cows within a herd, to an assortment of management practices of potential interest. The practical and logistical constraints of doing so constitute limitations to making direct recommendations on management strategies to jointly optimize both milk yield and reproductive performance. One could imagine identifying herds with relatively extreme estimates of the production-reproduction association and studying them retrospectively. These retrospective evaluations could be used to identify potentially important but previously overlooked management strategies conducive to, or just as importantly, detrimental to associations at both the cow and herd levels. Again, these evaluations do not necessarily render cause-and-effect inferences but would likely help identify potentially 
important management strategies to help guide future randomized studies.

Future work on the multifactorial nature of the production-reproduction association would benefit from incorporating information on herd health management and body condition. These two are arguably key components of dairy cow performance that are likely to be relevant in future investigations. Many herds keep individual cow records of vaccination schemes, clinical presentations of disease, treatment and outcomes, as well as accounts of regular evaluations of body condition throughout lactation. Many dairy managers find this information useful to guide decision making on individual cows or groups of cows. Unfortunately, health and body condition information is not standardly and routinely recovered by data processing centers, thus creating a breach between data available at the farm and those processed by the various centers. This disconnect may be partially reinforced by the lack of rigorous uniform standards for collecting health data across farms. Therefore, although health data may likely be meaningful within a given farm, the current lack of standardized practices for record keeping on health events limits the value of health data to make comparisons across farms, at least within the United States.

Another aspect of the heterogeneity in the production-reproduction association pertains to the long- versus short-term coverage of the outcomes used to characterize milk production and reproductive performance. Some of the newer evidence indicates that the mechanisms that underlie performance measures spanning a whole lactation (i.e., cumulative milk yield at $305 \mathrm{~d}$ and calving interval) may differ from the mechanisms at work for snapshot performance indicators corresponding to a shorter interval of time (i.e., daily milk yield at and pregnancy outcome to first PP insemination). Indeed, cows with greater lactation yields had longer calving intervals, but herd calving intervals were either shorter or unaffected among herds with highest cumulative 305-d yields (Laben et al., 1982; Nebel and McGilliard, 1993; Bello et al., 2012a). Conversely, herds with greater milk yields at the time of first insemination had impaired pregnancy rates, but within such herds, cows with higher daily yields were not any more or less likely to become pregnant to a given insemination than lower yielding herd mates (Bello, 2010). Clearly, the dual cow-herd components of the association between milk production and reproductive performance behave differently on a whole-lactation basis compared with a shorter period of time. It can certainly be speculated that a snapshot indicator may be more volatile and sensitive to rapid circumstantial changes in management, whereas the cumulative nature of whole-lactation indicators of performance is likely to make them more inferentially stable and reflective of long-term practices. Adjusting management recommendations to each short- and long-term scenario undoubtedly adds an extra layer of complexity to the challenge of jointly optimizing milk yield and reproductive performance of dairy cows.

\section{CONCLUSIONS}

In summary, understanding the multiple sources and levels of heterogeneity in the associations between milk yield and reproductive performance has direct implications for tailoring dairy management programs that optimize overall dairy cow performance in current production systems. Further interdisciplinary work that cuts across multiple areas of scientific expertise that is not bounded by geographical constraints is imperative in fully understanding the individual and combined contributions of each component for a comprehensive systems approach to dairy management. An appropriate allocation of funding to multi-herd and multi-state projects will be critical to accomplish these ambitious goals. Cutting-edge statistical tools are required to delineate the hierarchical biological and managerial subtleties of this relationship. It is only through a comprehensive appreciation of the multi-level and multifactorial sources of heterogeneity in the production-reproduction association that it will be possible to elicit management scenarios conducive to optimize both milk yield and reproductive efficiency of dairy cows.

\section{ACKNOWLEDGMENTS}

The authors appreciate the many insightful discussions with Juan Pedro Steibel and Ronald J. Erskine (Michigan State University, East Lansing) that have greatly contributed to this manuscript.

\section{REFERENCES}

Bauman, D. E., and W. B. Currie. 1980. Partitioning of nutrients during pregnancy and lactation-A review of mechanisms involving homeostasis and homeorhesis. J. Dairy Sci. 63:1514-1529.

Bello, N. M. 2010. Hierarchical Bayesian modeling of heterogeneity in the association between milk production and reproductive performance of dairy cows. PhD Diss. Department of Animal Science, Michigan State University, East Lansing.

Bello, N. M., J. P. Steibel, R. J. Erskine, and R. J. Tempelman. 2012a. Inferring upon heterogeneous associations in dairy cattle performance using a bivariate hierarchical model. J. Agric. Biol. Environ. Stat. 17:142-161.

Bello, N. M., J. P. Steibel, and R. J. Tempelman. 2010. Hierarchical Bayesian modeling of random and residual variance-covariance matrices in bivariate mixed effects models. Biom. J. 52:297-313.

Bello, N. M., J. P. Steibel, and R. J. Tempelman. 2012b. Hierarchical Bayesian modeling of heterogeneous cluster- and subject-level associations between continuous and binary outcomes in dairy production. Biom. J. 54:230-248. 
Berger, P. J., R. D. Shanks, A. E. Freeman, and R. C. Laben. 1981. Genetic aspects of milk yield and reproductive performance. J. Dairy Sci. 64:114-122.

Berry, D. P., F. Buckley, P. Dillon, R. D. Evans, M. Rath, and R. F. Veerkamp. 2003a. Genetic parameters for body condition score, body weight, milk yield, and fertility estimated using random regression models. J. Dairy Sci. 86:3704-3717.

Berry, D. P., F. Buckley, P. Dillon, R. D. Evans, M. Rath, and R. F. Veerkamp. 2003b. Genetic relationships among body condition score, body weight, milk yield, and fertility in dairy cows. J. Dairy Sci. 86:2193-2204.

Britt, J. H. 1975. Early postpartum breeding in dairy cows. A review. J. Dairy Sci. 58:266-271.

Butler, W. R. 1998. Review: Effect of protein nutrition on ovarian and uterine physiology in dairy cattle. J. Dairy Sci. 81:2533-2539.

Butler, W. R. 2003. Energy balance relationships with follicular development, ovulation and fertility in postpartum dairy cows. Livest. Prod. Sci. 83:211-218.

Cabrera, V. E., D. Solis, and J. del Corral. 2010. Determinants of technical efficiency among dairy farms in Wisconsin. J. Dairy Sci. 93:387-393.

Calus, M. P., J. J. Windig, and R. F. Veerkamp. 2005. Associations among descriptors of herd management and phenotypic and genetic levels of health and fertility. J. Dairy Sci. 88:2178-2189.

Capper, J. L., R. A. Cady, and D. E. Bauman. 2009. The environmental impact of dairy production: 1944 compared with 2007. J. Anim. Sci. 87:2160-2167.

Capper, J. L., E. Castaneda-Gutierrez, R. A. Cady, and D. E. Bauman. 2008. The environmental impact of recombinant bovine somatotropin (rbST) use in dairy production. Proc. Natl. Acad. Sci. USA $105: 9668-9673$.

Caraviello, D. Z., K. A. Weigel, P. M. Fricke, M. C. Wiltbank, M. J. Florent, N. B. Cook, K. V. Nordlund, N. R. Zwald, and C. L. Rawson. 2006. Survey of management practices on reproductive performance of dairy cattle on large US commercial farms. J. Dairy Sci. 89:4723-4735.

Cardoso, F. F., G. J. M. Rosa, J. P. Steibel, C. W. Ernst, R. O. Bates, and R. J. Tempelman. 2008. Selective transcriptional profiling and data analysis strategies for expression quantitative trait loci mapping in outbred F2 populations. Genetics 180:1679-1690.

Casella, G. 2008. Statistical Design. Springer Texts in Statistics. Springer, New York, NY.

Castillo-Juarez, H., P. A. Oltenacu, R. W. Blake, C. E. Mcculloch, and E. G. Cienfuegos-Rivas. 2000. Effect of herd environment on the genetic and phenotypic relationships among milk yield, conception rate, and somatic cell score in Holstein cattle. J. Dairy Sci. 83:807-814.

de los Campos, G., D. Gianola, P. Boettcher, and P. Moroni. 2006a. A structural equation model for describing relationships between somatic cell score and milk yield in dairy goats. J. Anim. Sci. 84:2934-2941.

de los Campos, G., D. Gianola, and B. Heringstad. 2006b. A structural equation model for describing relationships between somatic cell score and milk yield in first-lactation dairy cows. J. Dairy Sci. 89:4445-4455.

de Maturana, E. L., G. de los Campos, X. L. Wu, D. Gianola, K. A. Weigel, and G. J. M. Rosa. 2010. Modeling relationships between calving traits: A comparison between standard and recursive mixed models. Genet. Sel. Evol. 42:1. http://dx.doi.org/10.1186/12979686-42-1.

Eckles, C. H. 1929. A study of breeding records of dairy herds. Vol. 258. Bull. Agric. Exp. Stn. University of Minnesota, St. Paul.

Falconer, D. S. 1981. Introduction to Quantitative Genetics. 2nd ed. Longman, Essex, UK.

Fisher, R. A. 1926. The arrangement of field experiments. J. Min. Agric. Great Britain 33:503-513.

Gianola, D., and D. Sorensen. 2004. Quantitative genetic models for describing simultaneous and recursive relationships between phenotypes. Genetics 167:1407-1424.

Gilks, W. R., S. Richardson, and D. J. Spiegelhalter. 1996. Introducing Markov chain Monte Carlo. Pages 1-19 in Markov Chain Monte
Carlo in Practice. W. R. Gilks, S. Richardson, and D. J. Spiegelhalter, ed. Chapman and Hall, London, UK.

Greenland, S., and J. Robins. 1994. Ecologic studies-Biases, misconceptions, and counterexamples. Am. J. Epidemiol. 139:747-760.

Hansen, L. B., A. E. Freeman, and P. J. Berger. 1983. Yield and fertility relationships in dairy cattle. J. Dairy Sci. 66:293-305.

Ingvartsen, K. L., R. J. Dewhurst, and N. C. Friggens. 2003. On the relationship between lactational performance and health: Is it yield or metabolic imbalance that cause production diseases in dairy cattle? A position paper. Livest. Prod. Sci. 83:277-308.

Jasny, B. R., G. Chin, L. Chong, and S. Vignieri. 2011. Introduction to special section on data replication and reproducibility: Again, and again, and again.... Science 334:1225-1233.

Kadarmideen, H. N., R. Thompson, M. P. Coffey, and M. A. Kossaibati. 2003. Genetic parameters and evaluations from single- and multiple-trait analysis of dairy cow fertility and milk production. Livest. Prod. Sci. 81:183-195.

Knaus, W. 2009. Dairy cows trapped between performance demands and adaptability. J. Sci. Food Agric. 89:1107-1114.

König, S. X. L. Wu, D. Gianola, B. Heringstad, and H. Simianer. 2008. Exploration of relationships between claw disorders and milk yield in Holstein cows via recursive linear and threshold models. J. Dairy Sci. 91:395-406.

Laben, R. L., R. Shanks, P. J. Berger, and A. E. Freeman. 1982. Factors affecting milk yield and reproductive performance. J. Dairy Sci. 65:1004-1015.

LeBlanc, S. 2010. Assessing the association of the level of milk production with reproductive performance in dairy cattle. J. Reprod. Dev. 56:S1-S7.

Littell, R. C., G. A. Milliken, W. W. Stroup, R. D. Wolfinger, and O. Schabenberger. 2006. SAS for Mixed Models. 2nd ed. SAS Institute Inc., Cary, NC.

Little, R. J. A., and D. B. Rubin. 2002. Statistical Analysis with Missing Data. 2nd ed. Wiley Series in Probability and Statistics. John Wiley \& Sons, Inc., Hoboken, NJ.

Löf, E., H. Gustafsson, and U. Emanuelson. 2007. Associations between herd characteristics and reproductive efficiency in dairy herds. J. Dairy Sci. 90:4897-4907.

López-Gatius, F. 2003. Is fertility declining in dairy cattle? A retrospective study in northeastern Spain. Theriogenology 60:89-99.

López-Gatius, F., I. Garcia-Ispierto, P. Santolaria, J. Yaniz, C. Nogareda, and M. Lopez-Bejar. 2006. Screening for high fertility in high-producing dairy cows. Theriogenology 65:1678-1689.

Lucy, M. C. 2001. Reproductive loss in high-producing dairy cattle: Where will it end? J. Dairy Sci. 84:1277-1293.

Lucy, M. C. 2003. Mechanisms linking nutrition and reproduction in postpartum cows. Reprod. Suppl. 61:415-427.

Lucy, M. C., C. R. Staples, W. W. Thatcher, P. S. Erickson, R. M. Cleale, J. L. Firkins, J. H. Clark, M. R. Murphy, and B. O. Brodie. 1992. Influence of diet composition, dry matter intake, milk production and energy balance on time of postpartum ovulation and fertility in dairy cows. Anim. Prod. 54:323-331.

Lund, M. S., J. Jensen, and P. H. Petersen. 1999. Estimation of genetic and phenotypic parameters for clinical mastitis, somatic cell production deviance, and protein yield in dairy cattle using Gibbs sampling. J. Dairy Sci. 82:1045-1051.

Macmillan, K. L., I. J. Lean, and C. T. Westwood. 1996. The effects of lactation on the fertility of dairy cows. Aust. Vet. J. 73:141-147.

Mayeres, P., J. Stoll, J. Bormann, R. Reents, and N. Gengler. 2004. Prediction of daily milk, fat, and protein production by a random regression test-day model. J. Dairy Sci. 87:1925-1933.

McLean, R. A., W. L. Sanders, and W. W. Stroup. 1991. A unified approach to mixed linear models. Am. Stat. 45:54-64.

Miller, R. H., H. D. Norman, M. T. Kuhn, J. S. Clay, and J. L. Hutchison. 2007. Voluntary waiting period and adoption of synchronized breeding in dairy herd improvement herds. J. Dairy Sci. 90:1594-1606.

Morton, J. M. 2006. Potential bias in observed association between milk yield and reproductive performance in dairy cows. in Proc. 11th Int. Symp. Vet. Epidemiol. Econ. Accessed July 10, 2012. http://www.sciquest.org.nz/node/63741. 
Naik, G. 2011. Scientists' elusive goal: Reproducing study results. Wall Street Journal. December 2, 2011.

Nebel, R. L., and M. L. McGilliard. 1993. Interactions of high milk yield and reproductive performance in dairy cows. J. Dairy Sci. $76: 3257-3268$.

Neto, E. C., M. P. Keller, A. D. Attie, and B. S. Yandell. 2010. Causal graphical models in systems genetics: A unified framework for joint inference of causal network and genetic architecture for correlated phenotypes. Ann. Appl. Stat. 4:320-339.

NMPF. 2011. Dairy Producer Highlights. National Milk Producers Federation, Arlington, VA.

Norman, H. D., J. R. Wright, S. M. Hubbard, R. H. Miller, and J. L. Hutchison. 2009. Reproductive status of Holstein and Jersey cows in the United States. J. Dairy Sci. 92:3517-3528.

O'Hagan, A. 2004. Bayesian statistics: Principles and benefits. Pages 31-45 in Bayesian Statistics and Quality Modelling in the AgroFood Production Chain. Chapter 3. M. A. J. S. van Boekel, A. Stein, and A. H. C. van Bruggen, ed. Wageningen University and Research Center, Wageningen, the Netherlands.

Oltenacu, P. A., and D. M. Broom. 2010. The impact of genetic selection for increased milk yield on the welfare of dairy cows. Anim. Welf. 19:39-49.

Pearl, J. 2009 Causality: Models, Reasoning and Inference. 2nd ed. Cambridge University Press, Cambridge, UK.

Peters, M. W., and J. R. Pursley. 2002. Fertility of lactating dairy cows treated with Ovsynch after presynchronization injections of $\mathrm{PGF}_{2 \alpha}$ and GnRH. J. Dairy Sci. 85:2403-2406.

Pourahmadi, M. 1999. Joint mean-covariance models with applications to longitudinal data: Unconstrained parameterisation. Biometrika 86:677-690.

Pryce, J. E., M. D. Royal, P. C. Garnsworthy, and I. L. Mao. 2004 Fertility in the high-producing dairy cow. Livest. Prod. Sci. 86:125-135.

Richter, S. H., J. P. Garner, and H. Wurbel. 2009. Environmental standardization: Cure or cause of poor reproducibility in animal experiments? Nat. Methods 6:257-261.

Riley, R. D., K. R. Abrams, P. C. Lambert, A. J. Sutton, and J. R. Thompson. 2007. An evaluation of bivariate random-effects metaanalysis for the joint synthesis of two correlated outcomes. Stat. Med. 26:78-97.

Robinson, W. S. 1950. Ecological correlations and the behavior of individuals. Am. Sociol. Rev. 15:351-357.

Roche, J. F., D. Mackey, and M. D. Diskin. 2000. Reproductive management of postpartum cows. Anim. Reprod. Sci. 60-61:703-712.

Rosa, G. J. M., B. D. Valente, G. de los Campos, X. L. Wu, D. Gianola, and M. A. Silva. 2011. Inferring causal phenotype networks using structural equation models. Genet. Sel. Evol. 43:6.

Rosenbaum, P. R. 2010. Observational Studies. 2nd ed. Springer Series in Statistics. Springer, New York, NY.

Royal, M. D., A. O. Darwash, A. P. E. Flint, R. Webb, J. A. Woolliams, and G. E. Lamming. 2000. Declining fertility in dairy cattle: Changes in traditional and endocrine parameters of fertility. Anim. Sci. 70:487-501.

Sartori, R., J. M. Haughian, R. D. Shaver, G. J. Rosa, and M. C. Wiltbank. 2004. Comparison of ovarian function and circulating steroids in estrous cycles of Holstein heifers and lactating cows. J. Dairy Sci. 87:905-920.

Sartori, R., G. J. M. Rosa, and M. C. Wiltbank. 2002a. Ovarian structures and circulating steroids in heifers and lactating cows in summer and lactating and dry cows in winter. J. Dairy Sci. $85: 2813-2822$.

Sartori, R., R. Sartor-Bergfelt, S. A. Mertens, J. N. Guenther, J. J. Parrish, and M. C. Wiltbank. 2002b. Fertilization and early embryonic development in heifers and lactating cows in summer and lactating and dry cows in winter. J. Dairy Sci. 85:2803-2812.

Seykora, A. J., and B. T. McDaniel. 1983. Heritabilities and correlations of lactation yields and fertility for Holsteins. J. Dairy Sci. 66:1486-1493.

Shipley, B. 2002. Cause and Correlation in Biology: A User's Guide to Path Analysis, Structural Equations and Causal Inference. 1st ed. Cambridge University Press, Cambridge, UK.
Simmons, J. 2009. Technology's role in the 21st century: Food economics and consumer choice. Accessed Jan. 13, 2012. https://www. globaldairyinnovation.com/_layouts/downloads/Technology's\%20 Role\%20in\%20the\%2021st\%20Century\%20-\%20Food\%20Economics\%20and\%20Consumer\%20Choice.pdf.

Sorensen, D., and D. Gianola. 2002. Likelihood, Bayesian and MCMC Methods in Quantitative Genetics. Statistics for Biology and Health. Springer, New York, NY.

Sørensen, P., M. S. Lund, B. Guldbrandtsen, J. Jensen, and D. Sorensen. 2003. A comparison of bivariate and univariate QTL mapping in livestock populations. Genet. Sel. Evol. 35:605-622.

Spalding, R. W., R. W. Everett, and R. H. Foote. 1974. Fertility in New York artificially inseminated Holstein herds in dairy herd improvement. J. Dairy Sci. 58:718-723.

Spiegelhalter, D. J., N. G. Best, B. P. Carlin, and A. van der Linde. 2002. Bayesian measures of model complexity and fit. J. R. Stat. Soc. Series B Stat. Methodol. 64:1-34.

Stevenson, J. S. 2001. A review of oestrous behaviour and detection in dairy cows. Pages 43-62 in Fertility in the High-Producing Dairy Cow. Occasional Publication No. 26, Br. Soc. Anim. Sci. Vol. 1. Br. Soc. Anim. Sci., Penicuik, UK.

Tempelman, R. J. 2009. Invited review: Assessing experimental designs for research conducted on commercial dairies. J. Dairy Sci. 92:1-15.

Tenhagen, B. A., C. Vogel, M. Drillich, G. Thiele, and W. Heuwieser. 2003. Influence of stage of lactation and milk production on conception rates after timed artificial insemination following Ovsynch. Theriogenology 60:1527-1537.

Tranel, L., and P. Derdzinski. 2010. Hispanic dairy labor and culture. Accessed Dec. 2, 2011. http://www.extension.iastate.edu/NR/ rdonlyres/B090C051-8602-4456-B3D6-1ED769C2D495/46853/ HispanicDairyLaborPPT.pdf.

Tsuruta, S., I. Misztal, C. Huang, and T. J. Lawlor. 2009. Bivariate analysis of conception rates and test-day milk yields in Holsteins using a threshold-linear model with random regressions. J. Dairy Sci. 92:2922-2930.

Tsuruta, S., I. Misztal, and T. J. Lawlor. 2004. Genetic correlations among production, body size, udder, and productive life traits over time in Holsteins. J. Dairy Sci. 87:1457-1468.

Valente, B. D., G. J. M. Rosa, G. de los Campos, D. Gianola, and M. A. Silva. 2010. Searching for recursive causal structures in multivariate quantitative genetics mixed models. Genetics 185:633644

VanRaden, P. M., A. H. Sanders, M. E. Tooker, R. H. Miller, H. D. Norman. M. T. Kuhn, and G. R. Wiggans. 2004. Development of a national genetic evaluation for cow fertility. J. Dairy Sci. $87: 2285-2292$.

Varona, L., D. Sorensen, and R. Thompson. 2007. Analysis of litter size and average litter weight in pigs using a recursive model. Genetics 177:1791-1799.

Veerkamp, R. F., and B. Beerda. 2007. Genetics and genomics to improve fertility in high producing dairy cows. Theriogenology 68:S266-S273

Wiltbank, M., H. Lopez, R. Sartori, S. Sangsritavong, and A. Gumen. 2006. Changes in reproductive physiology of lactating dairy cows due to elevated steroid metabolism. Theriogenology 65:17-29.

Windig, J. J., M. P. Calus, B. Beerda, and R. F. Veerkamp. 2006. Genetic correlations between milk production and health and fertility depending on herd environment. J. Dairy Sci. 89:1765-1775.

Windig, J. J., M. P. Calus, and R. F. Veerkamp. 2005. Influence of herd environment on health and fertility and their relationship with milk production. J. Dairy Sci. 88:335-347.

Wu, X. L., B. Heringstad, and D. Gianola. 2010. Bayesian structural equation models for inferring relationships between phenotypes: A review of methodology, identifiability, and applications. J. Anim. Breed. Genet. 127:3-15.

Young, S. S., and A. Karr. 2011. Deming, data and observational studies: A process out of control and needing fixing. Pages 116-120 in Significance. Vol. 8. American Statistical Association, Alexandria, VA and Royal Statistical Society, London, UK. 